\title{
The effect of asymmetry of the coil block on self-assembly in ABC coil-rod-coil triblock copolymers
}

\author{
X.-G. Han1]; H.-H. Meng ${ }^{11}$, Y.-H. Ma ${ }^{1}$, S.-L. Ouyang ${ }^{2}$ \\ 1 School of Science, Inner Mongolia University of Science and Technology, Baotou 014010, China \\ 2 Inner Mongolia Key Laboratory for Utilization of Bayan Obo Multi-Metallic Resources: Elected State Key \\ Laboratory, Inner Mongolia University of Science and Technology, Baotou 014010, China
}

Received January 25, 2017, in final form June 5, 2017

\begin{abstract}
Using the self-consistent field approach, the effect of asymmetry of the coil block on the microphase separation is focused in $\mathrm{ABC}$ coil-rod-coil triblock copolymers. For different fractions of the rod block $f_{\mathrm{B}}$, some stable structures are observed, i.e., lamellae, cylinders, gyroid, and core-shell hexagonal lattice, and the phase diagrams are constructed. The calculated results show that the effect of the coil block fraction $f_{\mathrm{A}}$ is dependent on $f_{\mathrm{B}}$. When $f_{\mathrm{B}}=0.2$, the effect of asymmetry of the coil block is similar to that of the ABC flexible triblock copolymers; When $f_{\mathrm{B}}=0.4$, the self-assembly of $\mathrm{ABC}$ coil-rod-coil triblock copolymers behaves like rod-coil diblock copolymers under some condition. When $f_{B}$ continues to increase, the effect of asymmetry of the coil block reduces. For $f_{\mathrm{B}}=0.4$, under the symmetrical and rather asymmetrical conditions, an increase in the interaction parameter between different components leads to different transitions between cylinders and lamellae. The results indicate some remarkable effect of the chain architecture on self-assembly, and can provide the guidance for the design and synthesis of copolymer materials.
\end{abstract}

Key words: self-consistent field theory, rod-coil block copolymer, self-assembly

PACS: 61.25. $\mathrm{Hp}, 64.75 .+\mathrm{g}, 82.60 . \mathrm{Fa}$

\section{Introduction}

Block copolymers are macromolecules composed of chemically distinct subchains or blocks. The distinct blocks tend to phase separate, whereas the covalent bonds between distinct blocks prevent a macroscopic separation. The competition of these two opposing trends leads to the formation of various ordered phases [1]. From a fundamental point of view, the ordering in block copolymers provides an ideal paradigm for the study of self-organization in soft condensed matter [2]. From a technological point of view, the rich and fascinating ordered structures from block copolymers have found applications ranging from thermoplastic elastomers and high-impact plastics to pressure-sensitive adhesives, and so on. Compared with coil-coil block copolymers, rod-coil block copolymers have received much attention due to their abilities to self-assemble smaller scale structures in the field of novel functional and biomimetic materials [3, 4]. Especially, the rod-coil block copolymers containing conjugated rod building blocks offer opportunities for engineering electronic and optical devices [5-7].

In contrast to coil-coil block copolymers, rod-coil diblock copolymers have rich phase behaviors. Rodcoil block copolymers, as the simplest rod-coil block copolymers, self-assembled into ordered structures, e.g., zigzag lamellae [8], stripes [9], honeycombs [10], and hollow spherical and cylindrical micelles [11]. Compared with $\mathrm{AB}$ diblock copolymers, $\mathrm{ABC}$ triblock copolymers have more independent parameters controlling their phase behavior. The phase behavior of the two-component rod-coil block copolymers is controlled mainly by three parameters: the volume fraction of the rod block $f_{\mathrm{A}}$, the Flory-Huggins interaction between different blocks $\chi_{\mathrm{AB}}$, and the total degree of polymerization of the copolymer $N$.

\footnotetext{
*xghan0@163.com
} 
For $\mathrm{ABC}$ triblock copolymers, the number of parameters increases to six, including three interaction parameters $\chi_{\mathrm{AB}}, \chi_{\mathrm{BC}}$, and $\chi_{\mathrm{AC}}$; two independent volume fractions $f_{\mathrm{A}}$ and $f_{\mathrm{B}}$ and the total degree of polymerization of the copolymer $N$. This increased number of molecular variables will impose varieties and complexities on the self-assembly of the rod-coil block copolymers, meanwhile, leading to a great model system for engineering of a large number of intriguing nanostructures.

Some studies have centered on the microphase separation of rodlike-coil three-component block copolymers. Experimentally, Lee and coworkers [12,13] studied ABC coil-rod-coil triblock molecules, focusing the fraction of coil block on the order-order transition [12]. Zhou et al. [14] reported an ABC coil-coil-rod triblock containing liquid crystal polymer as the rod block, and found the formation of a liquid crystalline phase when the rod block achieved a certain length. Chang et al. [15] found that the rod-rod interaction lead to an order-disorder transition, and the lamellae appeared for $f_{\text {rod }} \simeq 0.2$ in $\mathrm{ABC}$ rod-coil-coil triblock copolymers. Theoretically, Xia et al. studied the self-assembly of ABC rod-coil-coil and coil-rod-coil triblock copolymers [16], constructing the phase $f_{\text {rod }}$ vs. $\chi_{N}$ phase diagram. Recently, $\mathrm{Li}$ et al. concentrated on the order-to-order phase transitions in coil-worm-coil triblock copolymers, suggesting that the tuning of the flexibility parameter provides a promising approach to design the resulting microphase-separated structures in semiflexible copolymer melts [17]. Although some literatures reported the effect of the fraction of end block on self-assembly, a systematic theoretical study on the molecularly asymmetry of the copolymers containing rigid blocks does not exist so far.

Due to the flexibility of adjusting system parameters, theory and simulation provide an ideal approach to explore the phase behavior of block copolymers. Mayes and Olvera de la Cruz [18], as well as Dobrynin and Erukhimovich [19] investigated flexible ABA triblock copolymers in the weak-segregation limit, providing evidence that molecular asymmetry can have a profound effect on both order-disorder and order-order transitions. Later on, Matsen used the self-consistent field theory [20] (SCFT) to show that such molecular asymmetry can alter microdomain dimensions and order-order transitions. Recently, Woloszczuk et al. employed on-lattice Monte Carlo simulations to examine the phase behavior of molecularly flexible asymmetric ABA copolymers in the limit of superstrong segregation, wherein interstitial micelles composed of the minority A endblock were observed to arrange into two-dimensional hexagonal arrays along the midplane of B-rich lamellae. These studies have demonstrated that molecular asymmetry is an important factor for self-assembly of block copolymers. In this work, we will systematically study the effect of the asymmetry of the coil block on self-assembly in the rod-coil block copolymers.

SCFT can be used to study rod-coil block copolymer systems. Pryamitsyn and Ganesan introduced Maier-Saupe theory [18, 19, 21, 22] to really account for the aligning interactions between rods, and the anisotropy interaction between rods presented considerable computational challenges. Some other theoretical models did not consider anisotropic interactions between the rods. For instance, Chen et al. [23], as well as Li and Gersappe [24] performed lattice-based SCFT simulations provided with computational advantage. The work of Chen et al. was the first time that SCFT predicted the hexagonal cylinder phase for rod-coil block copolymers. Subsequently Chen et al. used the SCFT lattice model to study the self-assembly of two-component rod-coil block copolymers [25.28] and studied firstly in theory three-component ones [16]. In this work, using SCFT lattice model, we concentrate on the effect of the volume fraction of the coil block on structure transition in the ABC coil-rod-coil triblock copolymers, providing for different rod block fractions. The paper is organized as follows: In section 2, we present the lattice model SCFT of coil-rod-coil triblock copolymers. The approach employs a two-stage relaxation procedure to evolve a system as rapidly as possible to a free-energy minimum similar to the literature [23]. In section 3, the calculated results are presented. These results are compared with those of previous works, especially with flexible ABC triblock copolymers. A brief conclusion will be given in section 4 .

\section{Theory}

We consider $n$ linear ABC coil-rod-coil triblock copolymers in a lattice, where the degree of polymerization of each chain is $N$. The $\mathrm{A}, \mathrm{B}$ and $\mathrm{C}$ segments have the same size and each segment occupies one lattice site. Thus, the total number of the lattice sites $N_{\mathrm{L}}$ equals $n\left(f_{\mathrm{A}}+f_{\mathrm{B}}+f_{\mathrm{C}}\right) N$. The system partition function can be expressed as 


$$
Z=\sum_{r(j, s), \alpha(j, s)}\left(\frac{1}{N_{\mathrm{L}}^{n}} \frac{1}{z^{n}} \prod_{j=1}^{n} \prod_{s=2}^{N} \lambda_{r_{j, s}-r_{j, s-1}^{\prime}}^{\alpha_{j, s-1}-\alpha_{j, s}^{\prime}}\right) \exp \left(-\frac{U}{k_{\mathrm{B}} T}\right)
$$

Here, $r_{j, s}$ and $\alpha_{j, s}$ denote the position and bond orientation of the $s$-th segment of the $j$-th copolymer, respectively. $r^{\prime}$ denotes the nearest neighboring site of $r . \alpha_{j, s}$ can choose all of the possible bond orientations, which depends on the selected lattice model. $z$ denotes lattice coordination number. The transfer matrix lambda depends only on the chain model used. This paper adopts an inflexion chain model. For a coil subchain,

$$
\lambda_{r_{j, s}-r_{j, s-1}^{\prime}}^{\alpha_{j, s-1}-\alpha_{j}^{\prime}}= \begin{cases}0, & \alpha_{j, s}=-\alpha_{j, s-1}^{\prime} \\ 1 /(z-1), & \text { otherwise. }\end{cases}
$$

For a rigid subchain,

$$
\lambda_{r_{j, s}-r_{j, s-1}^{\prime}}^{\alpha_{j, s-1}-\alpha_{j, s}^{\prime}}= \begin{cases}1, & \alpha_{j, s}=\alpha_{j, s-1}^{\prime} \\ 0, & \text { otherwise }\end{cases}
$$

Following the scheme of Scheutjens and Leemakers [29], the end-segment distribution function $G^{\alpha_{s}}(r, s \mid 1)$ presents a statistical weight of all possible configurations staring from segment 1, which can be located in any position within the lattice, ending at segment $s$ at site $r$, and satisfies the following recurrence relation:

$$
G^{\alpha_{s}}(r, s \mid 1)=G(r, s) \sum_{r_{s-1}^{\prime}} \sum_{\alpha_{s-1}^{\prime}} \lambda_{r_{s}-r_{s-1}^{\prime}}^{\alpha_{s-1} G^{\prime}} G^{\alpha_{s-1}}\left(r^{\prime}, s-1 \mid 1\right) .
$$

For all the values of $\alpha_{1}$, the initial condition is $G^{\alpha_{1}}(r, 1 \mid 1)=G(r, 1), G(r, s)$ is the weight factor of the free segment. It is expressed as $G(r, s)=\exp \left[-\omega_{\beta}\left(r_{s}\right)\right], s \in \beta(\beta=\mathrm{A}, \mathrm{B}, \mathrm{C})$. Another end-segment distribution function $G^{\alpha_{s}}(r, s \mid N)$ satisfies the following recurrence relation:

$$
G^{\alpha_{s}}(r, s \mid N)=G(r, s) \sum_{r_{s+1}^{\prime}} \sum_{\alpha_{s+1}^{\prime}} \lambda_{r_{s+1}^{\prime}-r_{s}}^{\alpha_{s+1}-\alpha_{s}^{\prime}} G^{\alpha_{s+1}}\left(r^{\prime}, s+1 \mid N\right)
$$

With the initial condition $G^{\alpha}(r, N \mid N)=G(r, N)$ for all the values of $\alpha_{N}$.

The free energy functional of $F$ (in the unit of $k_{\mathrm{B}} T$ ) in canonical ensemble is defined by

$$
\begin{aligned}
F= & \frac{1}{z} \sum_{r r^{\prime}}\left[\chi_{\mathrm{AB}} \phi_{\mathrm{A}}(r) \phi_{\mathrm{B}}\left(r^{\prime}\right)+\chi_{\mathrm{AC}} \phi_{\mathrm{A}}(r) \phi_{\mathrm{C}}\left(r^{\prime}\right)+\chi_{\mathrm{BC}} \phi_{\mathrm{B}}(r) \phi_{\mathrm{C}}\left(r^{\prime}\right)\right]-\sum_{r}\left[\omega_{\mathrm{A}}(r) \phi_{\mathrm{A}}(r)\right. \\
& \left.+\omega_{\mathrm{B}}(r) \phi_{\mathrm{B}}(r)+\omega_{\mathrm{C}}(r) \phi_{\mathrm{C}}(r)\right]-\sum_{r} \xi(r)\left[1-\phi_{\mathrm{A}}(r)-\phi_{\mathrm{B}}(r)-\phi_{\mathrm{C}}(r)\right]-n \ln Q,
\end{aligned}
$$

where

$$
Q=\frac{1}{N_{\mathrm{L}}} \frac{1}{z} \sum_{r_{N}} \sum_{\alpha_{N}} G^{\alpha^{N}}(r, N \mid 1) .
$$

Here, $\chi_{\mathrm{AB}}, \chi_{\mathrm{AC}}, \chi_{\mathrm{BC}}$ are the Flory-Huggins interaction parameters between different species. The $\phi_{k}(r)$ is the volume fraction field of block specie $k$, which is independent of the individual polymer configuration, and $\omega_{k}(r)$ is the chemical potential field conjugated to $\phi_{k}(r)$. The $\xi(r)$ is the potential field that ensures the incompressibility of the system, also known as a Lagrange multiplier.

Minimizing the free energy functional $F$ with respect to $\phi_{\mathrm{A}}, \phi_{\mathrm{B}}, \phi_{\mathrm{C}}, \omega_{\mathrm{A}}, \omega_{\mathrm{B}}, \omega_{\mathrm{C}}$ and $\xi(r)$ lead to the following SCFT equations:

$$
\begin{aligned}
& \omega_{\mathrm{A}}(r)=\frac{1}{z} \sum_{r^{\prime}} \chi_{\mathrm{AB}} \phi_{\mathrm{B}}\left(r^{\prime}\right)+\frac{1}{z} \sum_{r^{\prime}} \chi_{\mathrm{AC}} \phi_{\mathrm{C}}\left(r^{\prime}\right)+\xi(r), \\
& \omega_{\mathrm{B}}(r)=\frac{1}{z} \sum_{r^{\prime}} \chi_{\mathrm{BC}} \phi_{\mathrm{C}}\left(r^{\prime}\right)+\frac{1}{z} \sum_{r^{\prime}} \chi_{\mathrm{AB}} \phi_{\mathrm{A}}\left(r^{\prime}\right)+\xi(r),
\end{aligned}
$$




$$
\begin{aligned}
& \omega_{\mathrm{C}}(r)=\frac{1}{z} \sum_{r^{\prime}} \chi_{\mathrm{AC}} \phi_{\mathrm{A}}\left(r^{\prime}\right)+\frac{1}{z} \sum_{r^{\prime}} \chi_{\mathrm{BC}} \phi_{\mathrm{B}}\left(r^{\prime}\right)+\xi(r), \\
& \phi_{\mathrm{A}}(r)+\phi_{\mathrm{B}}(r)+\phi_{\mathrm{C}}(r)=1, \\
& \phi_{\mathrm{A}}(r)=\frac{1}{N_{\mathrm{L}}} \frac{1}{z} \frac{n}{Q} \sum_{s \in \mathrm{A}} \sum_{\alpha_{s}} \frac{G^{\alpha_{s}}(r, s \mid 1) G^{\alpha_{s}}(r, s \mid N)}{G(r, s)} \text {, } \\
& \phi_{\mathrm{B}}(r)=\frac{1}{N_{\mathrm{L}}} \frac{1}{z} \frac{n}{Q} \sum_{s \in \mathrm{B}} \sum_{\alpha_{s}} \frac{G^{\alpha_{s}}(r, s \mid 1) G^{\alpha_{s}}(r, s \mid N)}{G(r, s)} \\
& \phi_{\mathrm{C}}(r)=\frac{1}{N_{\mathrm{L}}} \frac{1}{z} \frac{n}{Q} \sum_{s \in \mathrm{C}} \sum_{\alpha_{s}} \frac{G^{\alpha_{s}}(r, s \mid 1) G^{\alpha_{s}}(r, s \mid N)}{G(r, s)} .
\end{aligned}
$$

In our calculations, the real-space method is implemented to solve the SCFT equations in a cubic lattice with periodic boundary conditions [16, 23]. The calculations begin from the initial potential fields generated by random functions, and stop when the free energy of the system changes within a tolerance of $10^{-8}$. By comparing the system free energies from different initial potential fields, we obtained stable phases in the system of ABC coil-rod-coil triblock copolymers.

\section{Result and discussion}

In our studies, we explore the effect of the asymmetry of the coil block on structural transition in ABC coil-rod-coil triblock copolymers. The interaction parameters between different species are the same, i.e., $\chi_{\mathrm{AB}}=\chi_{\mathrm{BC}}=\chi_{\mathrm{AC}}=\chi$, and the degree of the polymerization is $N=20$. Our calculations are preformed in the lattices of $N_{\mathrm{L}}=60^{3}$ and $N_{\mathrm{L}}=80^{3}$, and the emergence of the self-assembled structures are not constrained by system size. As showed in figure 1, some stable structures are observed, i.e., cylinders, core-shell hexagonal lattice (CSH) phase, lamellae and gyriod, and a perforated lamellae phase appears as a metastable structure. The phase diagrams for copolymers constructed by $f_{\mathrm{A}}$ versus $\chi N$ are shown in figure 2 for $f_{\mathrm{B}}=0.2,0.4,0.6$, and most of the regions of all the phase diagrams are occupied by lamellar phase. This indicates that the tolerance of the lamellae to chain architecture asymmetry is the highest of these stable phases in $\mathrm{ABC}$ triblock copolymers.

In the case of $f_{\mathrm{B}}=0.2$, and when $f_{\mathrm{A}}(=0.05,0.1)$ is small, among the three phase, i.e., micelles, $\mathrm{CSH}$ phase and lamellae, micelles are the most stable, and the $\mathrm{A}$ and $\mathrm{B}$ components coexist in the domain of a micelle. With an increase in $f_{\mathrm{A}}, \mathrm{CSH}$ phase $\left(0.15 \leqslant f_{\mathrm{A}} \leqslant 0.20\right)$, where the core and shell severally consist of $\mathrm{A}$ and $\mathrm{B}$ components, firstly becomes more stable, and then lamellae $\left(0.25 \leqslant f_{\mathrm{A}} \leqslant 0.40\right)$ are stable phase. For rod-coil diblock copolymers, at $f_{\mathrm{B}}=0.2$, lamellae are not observed, while micelles are observed. Therefore, the existence of a third block leads to the appearance of lamellae, which is confirmed by the flexible triblock copolymer [30]. The CSH phase and lamellae also appear in turn under the similar conditions in flexible ABC ones, but the A and B component-mixed phase is not observed. However, it is expected that micelles will change into $\mathrm{CSH}$ phase when the interaction parameter is rather big. Therefore, for $f_{\mathrm{B}}=0.2$, the effect of the length of the end block on microphase separation in $\mathrm{ABC}$ coil-rod-coil triblock copolymers is similar to that of the flexible ones.

For $f_{\mathrm{B}}=0.4$, when the two coil blocks are symmetrical, gyriod and cylinders can be found, gyriod is more stable in the small parameter region of $9 \leqslant \chi N \leqslant 13$. With an increase in $\chi N$, cylinders are more stable than gyriod. With the appearance of the asymmetry of the copolymers $\left(0.20 \leqslant f_{\mathrm{A}} \leqslant 0.25\right)$, gyriod is replaced by lamellar structure. When $\chi N \geqslant 14$, the free energy of the lamellae is higher than that of cylinders, and thus cylinders remain stable. When $f_{\mathrm{A}}=0.15,0.10$, the cylinder structure is also replaced by lamellae into the larger $\chi N$ region, and near the order-disorder transition, the copolymers self-assemble into gyriod again. When $f_{\mathrm{A}}=0.05$, cylinders are observed in a small $\chi N$ region, which is different from the case of the large $f_{\mathrm{A}}$. When $\chi N \geqslant 12$, lamellae are still observed. In the flexible $\mathrm{ABC}$ triblock copolymers, however, the three-color lamellae do not appear when $f_{\mathrm{A}}<0.1$. It is obvious that the appearance of lamellae at $f_{\mathrm{A}}=0.05$ results from the rigidity of the middle block copolymer of coil-rod-coil triblock copolymer. Accordingly, the chain stiffness is propitious to the occurrence of 

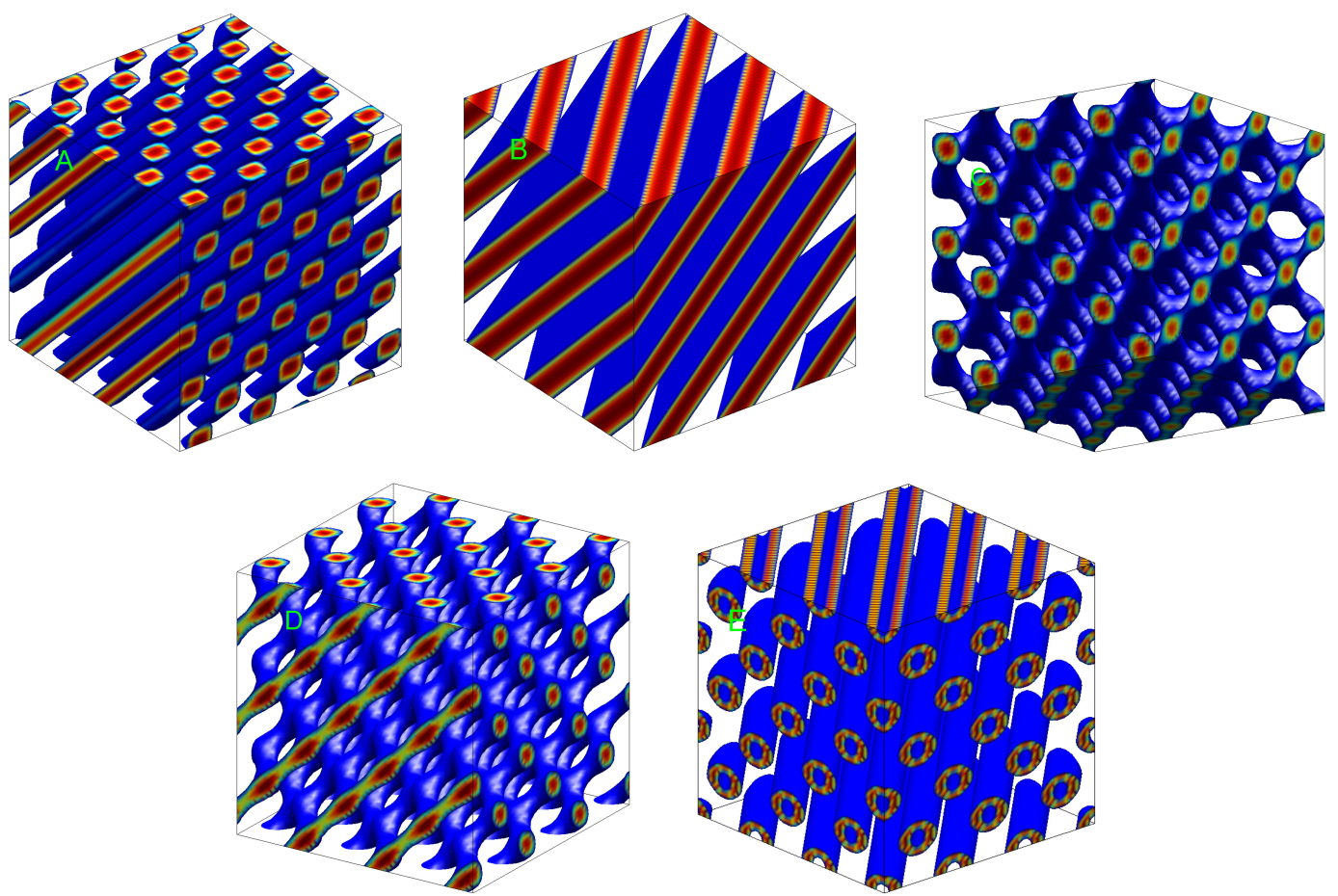

Figure 1. (Color online) The self-assembled structures of $A B C$ coil-rod-coil triblock copolymers: (a) cylinder (the components $\mathrm{A}$ and $\mathrm{C}$ are eliminated for clarity); (b) lamella (the components $\mathrm{A}$ and $\mathrm{C}$ are eliminated for clarity); (c) gyriod (the components A and B are eliminated for clarity); (d) perforated lamella phase (the components $\mathrm{A}$ and $\mathrm{C}$ are eliminated for clarity); (e) core-shell hexagonal lattice (the components $\mathrm{A}$ and $\mathrm{C}$ are eliminated for clarity).

lamellae, which is scrupulously discussed in bottlebrush block copolymers [31]. Furthermore, when $13 \leqslant \chi N \leqslant 16$, perforated lamellar phase is observed as a metastable structure. When $f_{\mathrm{A}}$ becomes small, the gyriod and cylinders sequentially appear for small $\chi N$, indicating that the self-assembly for the asymmetric coil-rod-coil triblock copolymers tends to be that of the coil-rod diblock copolymers, which is in detail discussed below. It is noted that with an increasing $\chi N$, the lamellar phase translates into cylinders for large $f_{\mathrm{A}}$, and vice versa at $f_{\mathrm{A}}=0.05$. The effect of the length of the end A block is concerned with the fraction of the middle rod block. For $f_{\mathrm{B}}=0.6$, the distribution of the ordered structures in a phase diagram [see figure 2 (c)] is similar to the one of $f_{\mathrm{B}}=0.4$ for large $f_{\mathrm{A}}$. It is shown that the effect of asymmetry of the end coil block on self-assembly will reduce when $f_{\mathrm{B}}$ continues to increase.

In order to clarify the difference of the above two transitions between lamellae and cylinders for $f_{\mathrm{B}}=0.4$, as shown in figure 3, the cylindrical phases for different $f_{\mathrm{A}}$ are compared below. When $f_{\mathrm{A}}=0.05$ and near the order-disorder transition, both $\mathrm{B}$ and $\mathrm{C}$ components self-assemble into two cylindrical domains which distribute symmetrically in the space [see figure 3(a)]. The rest of A component appears in the same region of B component as shown in figure 3 (c), since the volume fractions of A component are too small to appear alone in some space positions, where cylinders are similar to those of rod-coil diblock copolymers [23]. When $\chi N$ increases, the A component is separated from the domain of B component, and the lamellae become stable. In other words, the cylinder/lamella transition appears with an increasing $\chi N$. The reason for the formation of cylinders and the explanation for the transition between cylinders and lamellae are in detail discussed by Chremos and Theodorakis [32]. They proposed that a molecular asymmetry is required for the formation of cylindrical domains, and the cylinder/lamella transition results from the entropic penalty, which does apply to diblock copolymers. When $f_{\mathrm{A}}=0.05$, the coil-rod-coil triblock copolymers are very asymmetric and are regarded as diblock copolymer, and thus the cylinders form. The appearance of lamellae with $\chi N$ is due to the behavior of the triblock copolymer. It is obvious that herein the mechanism of the cylinder/lamella is different from the one 

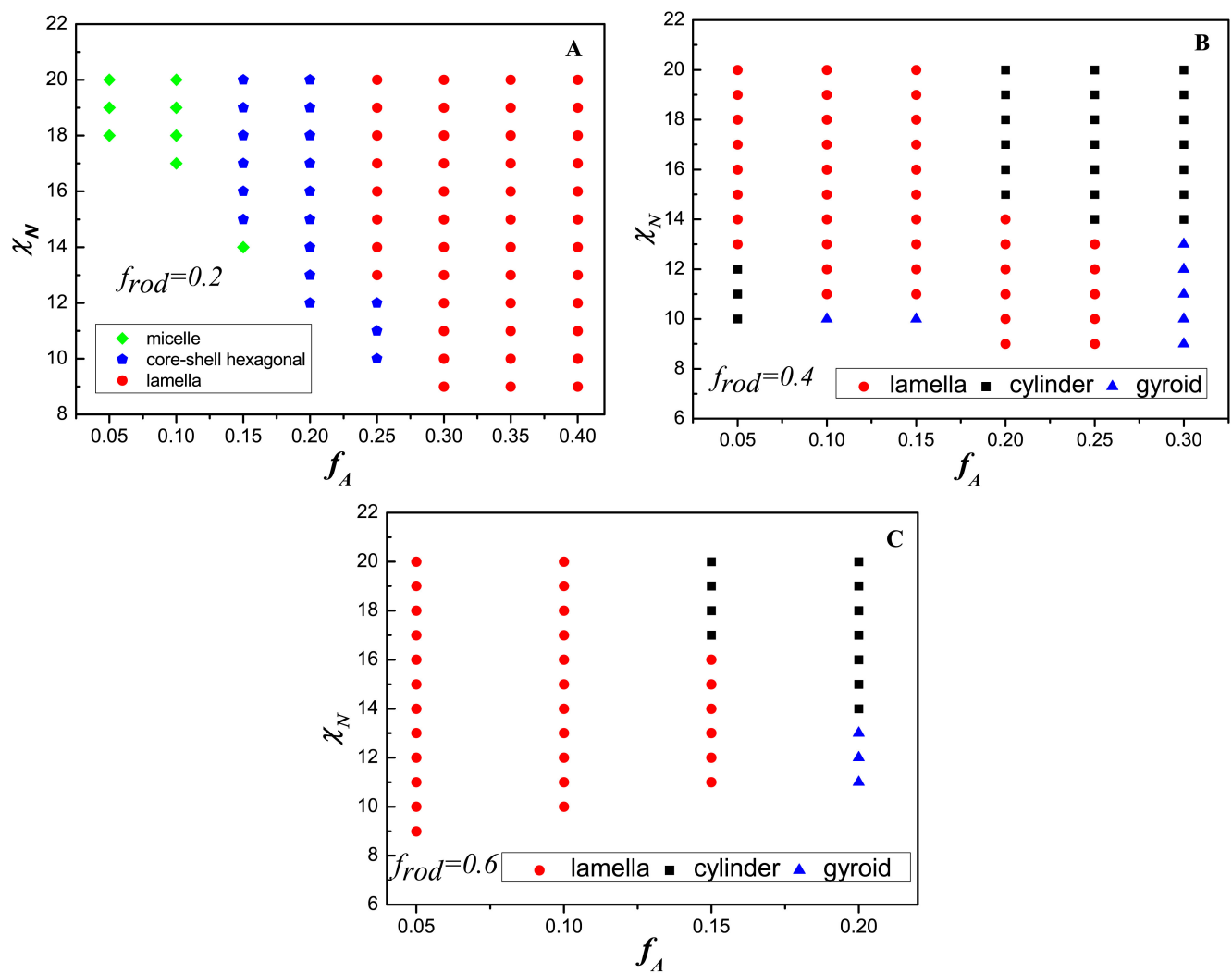

Figure 2. (Color online) The phase diagram for the $\mathrm{ABC}$ coil-rod-coil triblock copolymers with different length of the end A coil block when $f_{\mathrm{B}}=0.2,0.4,0.6$, respectively.

proposed by Chremos and Theodorakis. The appearance of the cylinder/lamella transition is to minimize the interaction energy among different components, which is in reasonable agreement with the same transition observed experimentally in rod-coil diblock copolymers [33].

By contrast, when $f_{\mathrm{A}}$ is large, only $\mathrm{B}$ component assembles into cylinders, and the $\mathrm{A}$ and $\mathrm{C}$ components appear alternately in the regions between the series of cylinders [see figure 3 (b) and (c)]. When $\chi N$ is small, the interface between different component domains is relatively thick, where the system tends to make more room for the coil block to maximize entropy. When $\chi N$ increases, the interface of lamellae tends to be thin to minimize the interaction energies between different components, and to simultaneously give rise to the configuration entropic penalty. Compared with lamellae, cylinders, where the rods are assembled into interdigitated bilayer structure [23], are favorable to the configuration entropy. Consequently, the cylinders are more stable than lamellar phase for large $\chi N$, i.e., the lamella/cylinder transition appears with $\chi N$.

\section{Conclusion and summary}

Using the self-consistent field approach, the effect of asymmetry of the coil block on the microphase separation is focused in $\mathrm{ABC}$ coil-rod-coil triblock copolymers. The calculated results show that the effect of the coil block fraction $f_{\mathrm{A}}$ is dependent on $f_{\mathrm{B}}$. When $f_{\mathrm{B}}$ is small, the effect of asymmetry of the coil block is similar to that of the $\mathrm{ABC}$ flexible triblock copolymers; When $f_{\mathrm{B}}$ is an intermediate value, the self-assembly of $\mathrm{ABC}$ coil-rod-coil triblock copolymers can behave like rod-coil diblock copolymers under rather asymmetrical conditions. When $f_{\mathrm{B}}$ is large, the effect of asymmetry of the coil block reduces. For intermediate $f_{\mathrm{B}}$, under the symmetrical and rather asymmetrical conditions, an increase in the interaction parameter between different components leads to different transitions between cylinders 

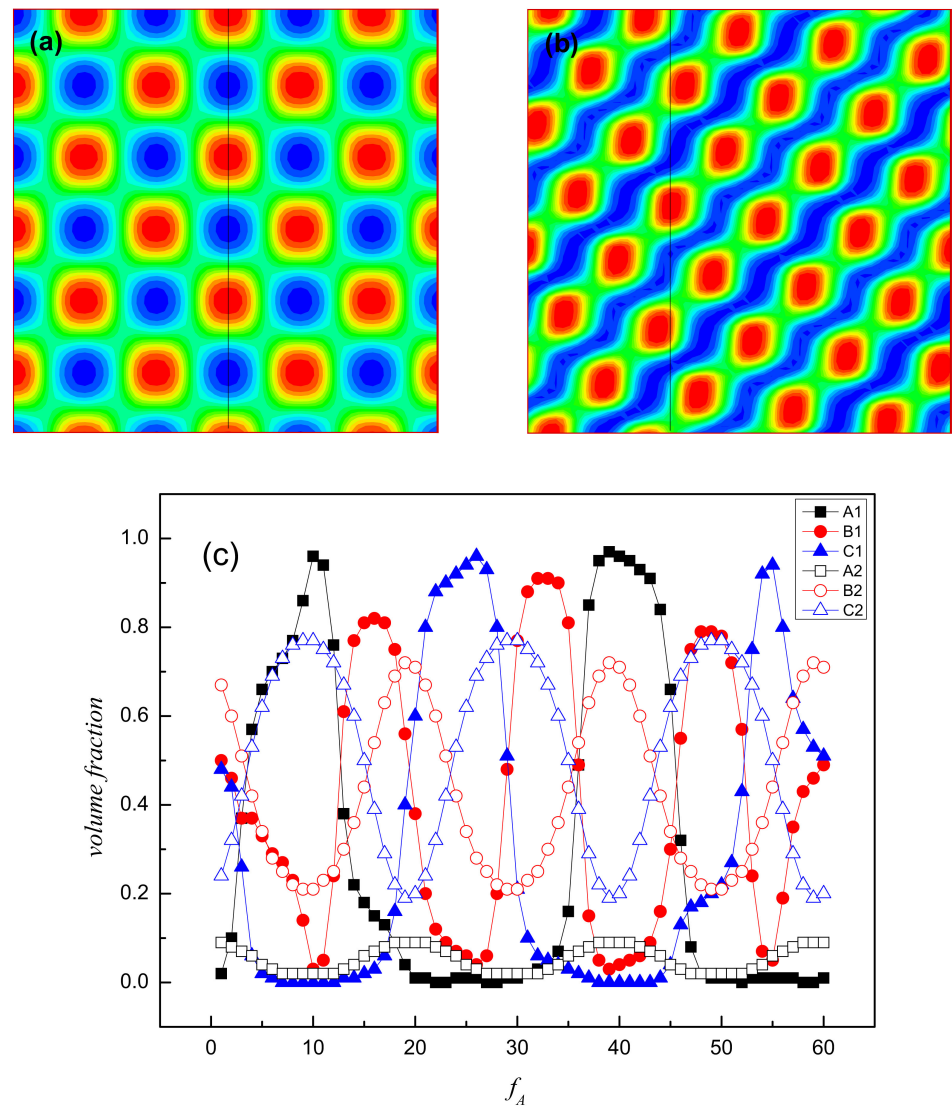

Figure 3. (Color online) Figures (a) and (b) are cross sections of the two cylindrical structures with $f_{\mathrm{A}}=0.05$ and $f_{\mathrm{A}}=0.3$, respectively. Figure (c) indicates the density changes of three components along the black line in the figures (a) and (b), the hollow and solid symbols correspond to $f_{\mathrm{A}}=0.05$ and $f_{\mathrm{A}}=0.3$, respectively.

and lamellae. In rod-coil ABC systems, the asymmetric interaction parameters can also be tuned up. It is expected that the interesting morphologies can form in the self-assembly under the conditions of asymmetric interactions, which is demonstrated by the ABC coil-coil-coil triblock copolymers [30, 34]. This investigation will be implemented in the subsequent work.

\section{Acknowledgements}

This research is financially supported by the National Nature Science Foundations of China (21564011), the Nature Science Foundations of the Inner Mongolia municipality (2017MS(LH)0211), and the Graduate Education Innovation Program of the Inner Mongolia Autonomous Province (S20161012707).

\section{References}

1. Hamley I.W., Developments in Block Copolymer Science and Technology, Wiley, New York, 2004, doi $10.1002 / 0470093943$. fmatter

2. Hamley I.W., The Physics of Block Copolymers, Oxford University Press, Oxford, 1998.

3. Lecommandoux S., Achard M.F., Langenwalter J.F., Klok H.A., Macromolecules, 2001, 34, 9100-9111, doi $10.1021 / \mathrm{ma} 010940 \mathrm{j}$ 
4. Łosik M., Kubowicz S., Smarsly B., Schlaad H., Eur. Phys. J. E, 2004, 15, 407-411, doi $10.1140 /$ epje/i2004-10057-5

5. Ball Z.T., Sivula K., Fréchet J.M.J., Macromolecules, 2006, 39, 70-72, doi $10.1021 / \mathrm{ma} 052325 \mathrm{~b}$

6. Van De Wetering K., Brochon C., Ngov C., Hadziioannou G., Macromolecules, 2006, 39, 4289-4297, doi $10.1021 / \mathrm{ma} 060497 \mathrm{i}$

7. Dai C.A., Yen W.C., Lee Y.H., Ho C.C., Su W.F., J. Am. Chem. Soc., 2007, 129, 11036-11038, doi $10.1021 / \mathrm{ja} 0733991$.

8. Chen J.T., Thomas E.L., Ober C.K., Hwang S.S., Macromolecules, 1995, 28, 1688-1697, doi $10.1021 / \mathrm{ma} 00109 \mathrm{a} 048$

9. Radzilowski L.H., Carragher B.O., Stupp S.I., Macromolecules, 1997, 30, 2110-2119, doi 10.1021/ma9609700

10. Lee M., Cho B.K., Ihn K.J., Lee W.K., Oh N.K., Zin W.C., J. Am. Chem. Soc., 2001, 123, 4647-4648, doi $10.1021 / \mathrm{ja} 004071+$.

11. Jenekhe S.A., Chen X.L., Science, 1998, 279, No. 5358, 1903-1907, doi 10.1126/science.279.5358.1903

12. Lee M., Lee D.W., Cho B.K., Yoon J.Y., Zin W.C., J. Am. Chem. Soc., 1998, 120, 13258, doi 10.1021/ja9823619

13. Oh N.K., Zin W.C., Im J.H., Lee M., Polymer, 2006, 47, 5275-5286, doi 10.1016/j.polymer.2006.05.039.

14. Zhang H., Sun X., Wang X., Zhou Q.F., Macromol. Rapid Commun., 2005, 26, 407-411, doi $10.1002 / \mathrm{marc} .200400506$

15. Chang C.J., Lee Y.H., Chen H.L., Chiang C.H., Hsu H.F., Ho C.C., Su W.F., Dai C.A., Soft Matter, 2011, 7, 10951-10960, doi $10.1039 / \mathrm{c} 1 \mathrm{sm} 05926 \mathrm{~b}$

16. Xia Y.D., Chen J.Z., Sun Z.Y., Shi T.F., An L.J., Jia Y.X., Polymer, 2010, 51, 3315-3319, doi $10.1016 /$ j.polymer.2010.04.063

17. Li S.B., Jiang Y., Chen J.Z.Y., J. Chem. Phys., 2016, 145, 184902, doi:10.1063/1.4967423

18. Gao J., Tang P., Yang Y.L., Soft Matter, 2013, 9, 69-81, doi 10.1039/C2SM26758F

19. Li S.B., Jiang Y., Chen J.Z.Y., Soft Matter, 2014, 10, 8932-8944, doi:10.1039/C4SM01884B

20. Matsen M.W., Schick M., Phys. Rev. Lett., 1994, 72, 2660, doi $10.1103 /$ PhysRevLett.72.2660

21. Pryamitsyn V., Ganesan V., J. Chem. Phys., 2004, 120, 5824-5838, doi 10.1063/1.1649729.

22. Jiang Y., Chen J.Z.Y., Phys. Rev. Lett., 2013, 110, 138305, doi:10.1103/PhysRevLett.110.138305

23. Chen J.Z., Zhang C.X., Sun Z.Y., Zheng Y.S., An L.J., J. Chem. Phys., 2006, 124, 104907, doi $10.1063 / 1.2176619$

24. Li W.T., Gersappe D., Macromolecules, 2001, 34, 6783-6789, doi $10.1021 / \mathrm{ma010194i}$

25. Chen J.Z., Zhang C.X., Sun Z.Y., An L.J., Tong Z., J. Chem. Phys., 2007, 127, 024105, doi $10.1063 / 1.2750337$

26. Chen J.Z., Sun Z.Y., Zhang C.X., An L.J., Tong Z., J. Chem. Phys., 2008, 128, 074904, doi 10.1063/1.2831802

27. Xia Y.D., Sun Z.Y., Shi T.F., Chen J.Z., An L.J., Jia Y.X., Polymer, 2008, 49, 5596-5601, doi $10.1016 /$ j.polymer.2008.09.059

28. Xia Y.D., Chen J.Z., Sun Z.Y., Shi T.F., An L.J., Jia Y.X., J. Chem. Phys., 2009, 131, 144905, doi $10.1063 / 1.3247192$

29. Leermakers F.A.M., Scheutjens J.M.H.M., J. Chem. Phys., 1988, 89, 3264, doi 10.1063/1.454931

30. Tang P., Qiu F., Zhang H.D., Yang Y.L., Phys. Rev. E, 2004, 69, 031803, doi 10.1103/PhysRevE.69.031803

31. Chremos A., Theodorakis P.E., Polymer, 2016, 97, 191-195, doi 10.1016/j.polymer.2016.05.034

32. Chremos A., Theodorakis P.E., ACS Macro Lett., 2014, 3, 1096-1100, doi: 10.1021/mz500580f

33. Shi L.Y., Shen Z.H., Fan X.H., Macromolecules, 2011, 44, 2900-2907, doi 10.1021/ma1023704

34. Tyler C.A., Qin J., Bates F.S., Morse D.C., Macromolecules, 2007, 40, 4654, doi $10.1021 / \mathrm{ma} 062778$ w 


\title{
Вплив асиметрії виткоподібного блоку на самоскупчення у АВС виток-стержень-виток триблокових кополімерах
}

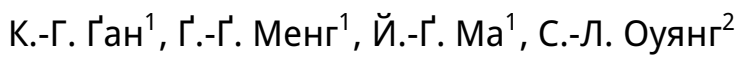 \\ 1 Вища школа природничих наук, Університет науки і технологій внутрішньої Монголії, \\ Баоту 014010, Китай \\ 2 Головна лабораторія інтегрованого використання мультиметалічних ресурсів Баян Обо, Університет \\ науки і технології внутрішньої Монголії, Баоту 014010, Китай
}

\begin{abstract}
Використовуючи самоузгоджений польовий підхід, описано вплив асиметрії виткоподібного блоку на мікрофазне розділення в АВС триблокових кополімерах виток-стержень-виток. Для різних фракцій стержневого блоку $f_{\mathrm{B}}$, спостерігаються стійкі структури, а саме ламели, циліндри, гіроїд і гексагональна ґратка сердечник-оболонка, а також побудовані фазові діаграми. Результати обчислень показують, що ефект фракції виткоподібного блоку $f_{\mathrm{A}}$ залежить від $f_{\mathrm{B}}$. Коли $f_{\mathrm{B}}=0.2$, тоді вплив асиметрії виткоподібного блоку $\epsilon$ подібним до ефекту АВС гнучких триблокових кополімерів. Коли $f_{\mathrm{B}}=0.4$, тоді самоскупчення АВС виток-стержень-виток триблокових кополімерів відбувається подібно до двоблокових кополімерів стержень-виток за певних умов. Коли $f_{\mathrm{B}}$ продовжує зростати, тоді вплив асиметрії виткоподібного блоку зменшується. При $f_{\mathrm{B}}=0.4$, за симетричних та доволі асиметричних умов, збільшення параметра взаємодії між різними компонентами призводить до різних переходів між циліндрами та ламелами. Результати вказують на деякий значний вплив ланцюжкової архітектури на самоскупчення, що може бути керівництвом для розробки та синтезу кополімерних матеріалів.
\end{abstract}

Ключові слова: самоузгоджена польова теорія, стержень-виток блоковий кополімер, самоскупчення 


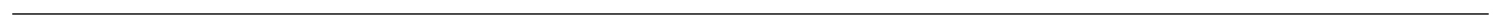

